Article

\title{
Tuning the Linear and Nonlinear Optical Properties of Pyrene-Pyridine Chromophores by Protonation and Complexation to $\mathrm{d}^{10}$ Metal Centers $\S$
}

\author{
Elena Lucenti ${ }^{1, *}\left(\mathbb{D}\right.$, Alessandra Forni ${ }^{1}{ }^{(}$, Daniele Marinotto ${ }^{1}$, Andrea Previtali ${ }^{2}$, \\ Stefania Righetto ${ }^{2}$ and Elena Cariati ${ }^{1,2, *}$ \\ 1 Institute of Molecular Science and Technologies of CNR and INSTM RU, via Golgi 19, 20133 Milano, Italy; \\ a.forni@istm.cnr.it (A.F.); daniele.marinotto@istm.cnr.it (D.M.) \\ 2 Department of Chemistry, Università degli Studi di Milano and INSTM RU, via Golgi 19, 20133 Milano, Italy; \\ andrea.previtali@unimi.it (A.P.); stefania.righetto@unimi.it (S.R.) \\ * Correspondence: e.lucenti@istm.cnr.it (E.L.); elena.cariati@unimi.it (E.C.); \\ Tel.: +39-02-503-14369 (E.L.); +39-02-503-14370 (E.C.) \\ $\S$ This manuscript is dedicated to Prof. Renato Ugo, on the occasion of his 80th birthday, for his fundamental \\ research in the field of organic and hybrid inorganic/organic materials with second-order NLO properties.
}

Received: 17 January 2019; Accepted: 5 March 2019; Published: 9 March 2019

check for updates

\begin{abstract}
The linear and second-order nonlinear optical (NLO) properties of two pyrene-pyridine chromophores, namely, 4-(pyren-1-yl)pyridine $\left(\mathbf{L}_{1}\right)$ and 4-(2-(pyren-1-yl)ethyl)pyridine $\left(\mathbf{L}_{2}\right)$, were investigated and modulated by performing protonation/deprotonation cycles or by complexation to $\mathrm{d}^{10}$ metal centers such as $\mathrm{Zn}(\mathrm{II})$ and $\mathrm{Cu}(\mathrm{I})$ to form the monomeric $\left[\mathrm{Zn}\left(\mathrm{CH}_{3} \mathrm{CO}_{2}\right)_{2}\left(\mathbf{L}_{1}\right)_{2}\right]$ complex and the $\left[\mathrm{CuI}\left(\mathbf{L}_{2}\right)\right]_{n}$ coordination polymer, respectively. The structures of $\mathbf{L}_{1}, \mathbf{L}_{2},\left[\mathrm{Zn}\left(\mathrm{CH}_{3} \mathrm{CO}_{2}\right)_{2}\left(\mathbf{L}_{1}\right)_{2}\right]$ and $\left[\mathrm{CuI}\left(\mathbf{L}_{2}\right)\right]_{n}$ were determined by means of single-crystal X-ray diffraction studies. The NLO response, measured by the electric-field-induced second harmonic generation (EFISH) technique, was positive for both chromophores and showed an inversion of the sign after exposure to $\mathrm{HCl}$ vapors. This process was completely reversible and the original values were restored by simple exposure to $\mathrm{NH}_{3}$ vapors. Coordination of $\mathbf{L}_{1}$ to $\mathrm{Zn}$ (II) also resulted in a negative NLO response, although smaller in magnitude compared to the protonated form, due to the weak Lewis acidity of the " $\mathrm{Zn}\left(\mathrm{CH}_{3} \mathrm{CO}_{2}\right)_{2}$ " fragment. The results were also interpreted on the basis of DFT/TDDFT calculations.
\end{abstract}

Keywords: second-order nonlinear optics; EFISH technique; pyrene-pyridine chromophores; acidochromism

\section{Introduction}

In recent years compounds with second-order nonlinear optical (NLO) properties have received increasing attention due to their potential use in optical communications, signal processing, data storage and electro-optical devices [1,2]. In this context, pyridine-based chromophores have been extensively studied as promising building blocks for the preparation of bulk organic materials [3] and coordination networks [4], or at the molecular level for the syntheses of organometallic complexes [5]. In particular, the investigation of $\operatorname{Cr}(0), \mathrm{W}(0), \operatorname{Rh}(\mathrm{I}), \operatorname{Ir}(\mathrm{I})$, and $\mathrm{Os}(\mathrm{II})$ complexes with para-substituted pyridines has revealed the possibility of tuning the second-order NLO response of the ligand depending on the electron properties and oxidation state of the metal center or on the ligand environment $[6,7]$. It has been shown that, according to the electron-withdrawing strength of the substituents on the pyridine ring, the metal center plays an ambivalent role in acting as an electron donor through metal-to-ligand (MLCT) charge-transfer transition or as an electron acceptor [5]. 
More recently, pyridine-based chromophores have been investigated as acidochromes for their ability to switch their second-order NLO response, both at molecular and macroscopic levels, in response to protonation-deprotonation cycles [8,9]. Interestingly, the introduction of a rigid $\pi$-delocalized system such as pyrene in 4-(2-(pyren-1-yl)vinyl)pyridine (PVP, see Scheme 1 for its chemical structure) affords a simple and highly transparent chromophore characterized by unexpected and tunable second-order NLO properties. An investigation on the reversible switch of the luminescence and NLO properties of PVP upon exposure to $\mathrm{HCl}$ or $\mathrm{NH}_{3}$ vapors has revealed that the pyrene moiety has a role in the NLO response of the chromophore [8].
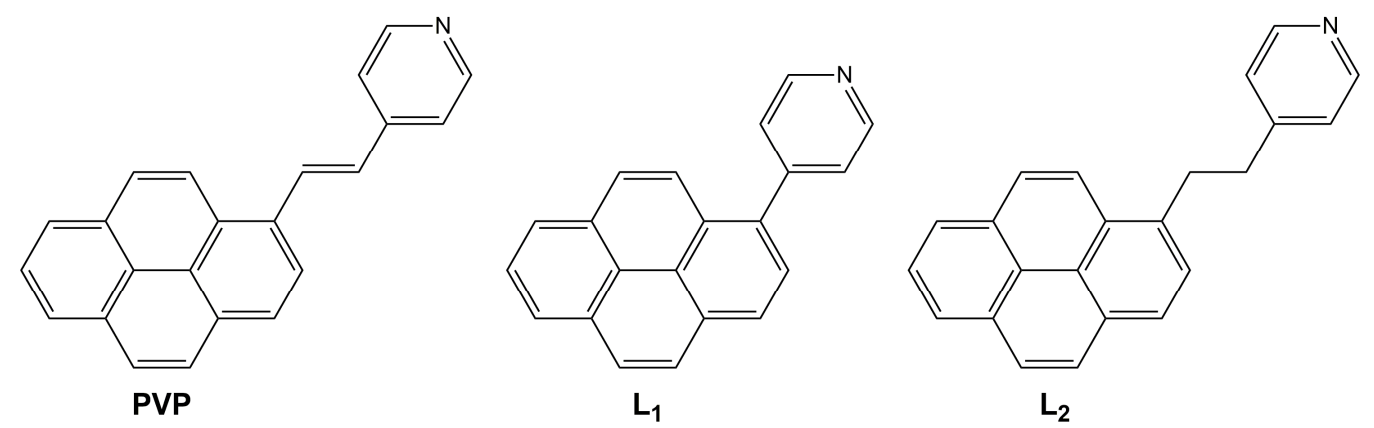

Scheme 1. Chemical structures of PVP, 4-(pyren-1-yl)pyridine ( $\left.\mathbf{L}_{\mathbf{1}}\right)$, and 4-(2-(pyren-1-yl)ethyl)pyridine $\left(\mathbf{L}_{\mathbf{2}}\right)$.

In this work, the study of the NLO properties of pyrene-pyridine chromophores is extended to the push-pull derivative 4-(pyren-1-yl)pyridine $\left(\mathbf{L}_{1}\right.$, see Scheme 1$)$, in which the pyridine is directly bound to the pyrene moiety, and to 4-(2-(pyren-1-yl)ethyl)pyridine $\left(\mathbf{L}_{2}\right.$, see Scheme 1), where the conjugation between the aromatic systems is lost due to the interconnecting dimethylene bridge. Despite their simple structure, it is interesting that there are few reports in the literature regarding these two ligands. $\mathbf{L}_{\mathbf{1}}$ has been recently described for the synthesis of a $\mathrm{Ru}^{\mathrm{II}}$ complex investigated as catalyst in water oxidation, the pyrenyl moiety being used for anchoring on multi-walled carbon nanotubes via $\pi$-stacking interactions [10]. The pyrenyl group has been also exploited in $\mathbf{L}_{\mathbf{1}}$ for the preparation of fluorescent probes bound to the proteins of the inner mitochondrial membranes of HeLa cells [11], or in $\mathbf{L}_{2}$ for fluorescent sensing of transition metal ions [12,13]. To our knowledge there are no reports in the literature on the second-order NLO response of these two ligands. Here, by means of the electric-field-induced second harmonic generation (EFISH) technique, we investigated how the NLO properties of $\mathbf{L}_{\mathbf{1}}$ and $\mathbf{L}_{\mathbf{2}}$ can be tuned either by performing protonation/deprotonation cycles, or by coordination to $\mathrm{d}^{10}$ metal centers such as $\mathrm{Cu}(\mathrm{I})$ and $\mathrm{Zn}(\mathrm{II})$.

\section{Results and Discussion}

\subsection{Synthesis and Characterization of $\mathbf{L}_{1},\left[\mathbf{L}_{\mathbf{1}} \mathbf{H}\right]^{+}$, and $\mathrm{Zn} \mathbf{L}_{1}$}

Compound $\mathbf{L}_{1}$ was synthesized by a slight modification, as reported in the literature [10] by Suzuki-Miyaura cross-coupling between 1-bromopyrene and 4-pyridinylboronic acid (Scheme 2). Single crystals of $\mathbf{L}_{\mathbf{1}}$ (see Figure 1a and Figure S4, Table S1) were obtained by slow evaporation of a dichloromethane/ $\mathrm{MeOH}$ solution. X-ray diffraction studies revealed a partial conjugation between pyrene and pyridine, as deduced by both the length of the bond connecting the two moieties, $\mathrm{r}(\mathrm{C} 1-\mathrm{C} 17)$ $=1.486 \AA$, and the dihedral angle between the least-squares (l.s.) planes through their respective heavy atoms $\left(\theta=53.18^{\circ}\right)$. Molecules of $\mathbf{L}_{\mathbf{1}}$ pack in a herringbone fashion, forming infinite chains along the crystallographic axis $\mathrm{b}$ through $\mathrm{C}-\mathrm{H} \cdots \pi$ hydrogen bonds involving pyrene units (distance between $\mathrm{H} 4$ and the pyrene 1.s. plane equal to $2.69 \AA$ ). These chains are laterally connected through weak $\mathrm{C}-\mathrm{H} \cdots \mathrm{N}$ hydrogen bonds in one direction and, in the other direction, $\mathrm{C}-\mathrm{H} \cdots \pi$ hydrogen bonds and $\pi \cdots \pi$ interactions between pyrene units. The closest distances between pyrene l.s. planes, $3.550 \AA$, 
and the respective centroids, $4.099 \AA$, are similar to those of the pyrene structure itself ( 3.53 and $3.95 \AA$, respectively) [14].

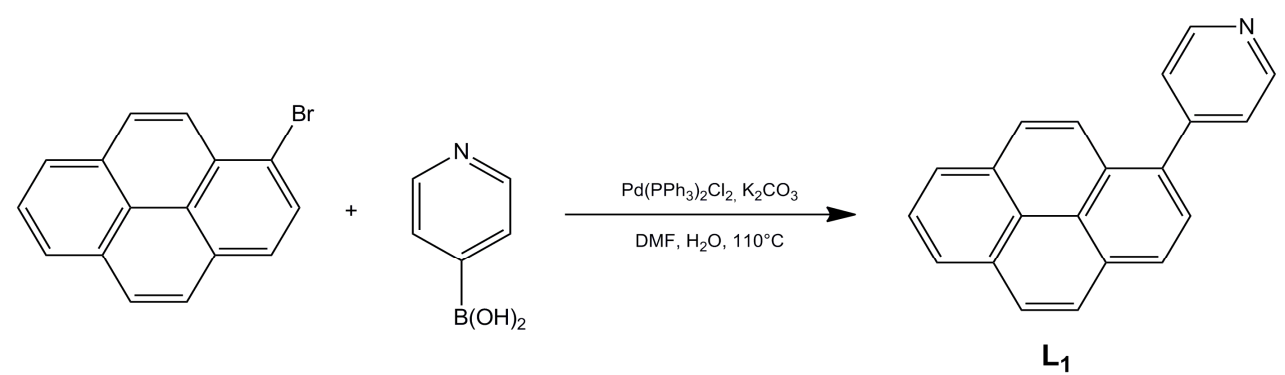

Scheme 2. Synthesis of $\mathbf{L}_{\mathbf{1}}$.
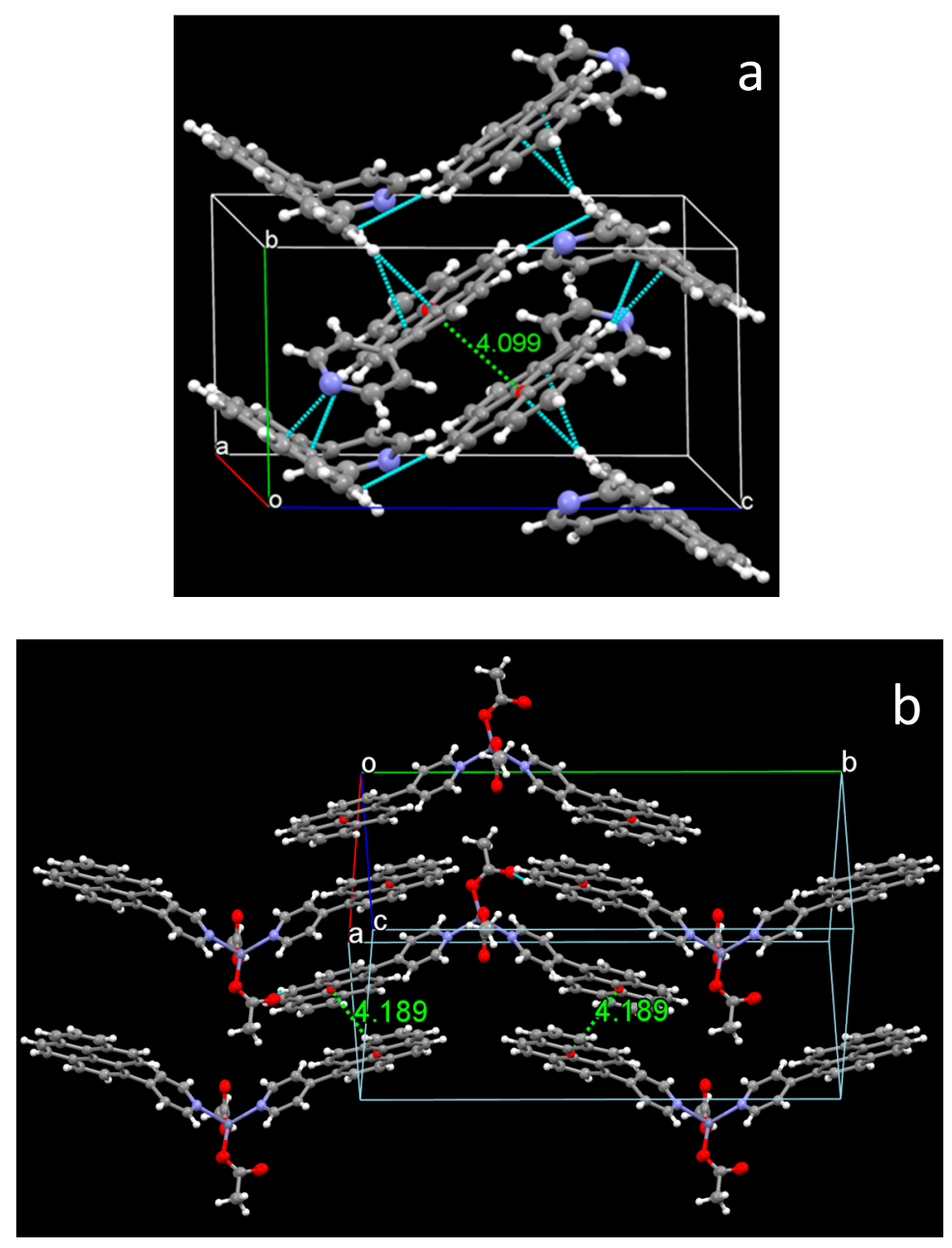

Figure 1. Fragments of the crystal packing of (a) $\mathbf{L}_{\mathbf{1}}$ (viewed approximately along the a direction) and (b) $\mathrm{ZnL}_{1}$ (viewed approximately along the ac direction) showing hydrogen bonds (light blue dashed lines) and distance between centroids of the pyrene units (green dashed line). Ellipsoids drawn at $30 \%$ probability.

The UV-visible absorption spectrum of $\mathrm{L}_{1}$ in $\mathrm{CHCl}_{3}$ (treated overnight with basic $\mathrm{Al}_{2} \mathrm{O}_{3}$ ), showing an absorption edge at $345 \mathrm{~nm}$ and vibronic system at 280 and $270 \mathrm{~nm}$, was very similar to that of pyrene itself, though slightly red-shifted and with a partial loss of the vibronic resolution (see Figure 2a), but greatly different from that of PVP. In fact, the latter shows a broad low-energy band at $378 \mathrm{~nm}$ associated with an intramolecular charge transfer (ICT) transition emanating from pyrene towards the 
pyridine moiety [8]. However, similarly to what was previously observed for PVP, the exposure of the $\mathrm{CHCl}_{3}$ solution of $\mathbf{L}_{1}$ to $\mathrm{HCl}$ vapors for a few minutes resulted in a significant red shift $(410 \mathrm{~nm}$, see Figure 2a) of the absorption maximum due to the formation of $\left[\mathbf{L}_{1} \mathbf{H}\right]^{+}$, which displayed a ICT transition from pyrene to pyridine occurring at higher energy with respect to [PVPH] ${ }^{+}(443 \mathrm{~nm})$, in agreement with its reduced conjugation length. The reverse transformation was observed by treating the solution with $\mathrm{NH}_{3}$ vapors for a few minutes. The protonation process also strongly affected the photoluminescent behavior of $\mathbf{L}_{1}$ in $\mathrm{CHCl}_{3}$ solution. The initial 390 and $407 \mathrm{~nm}$ emission bands of $\mathbf{L}_{\mathbf{1}}$ pyrene moiety were in fact shifted to $482 \mathrm{~nm}$ after being exposed to $\mathrm{HCl}$ vapors (see Figure $2 b$ ) and restored by treatment with ammonia vapors.

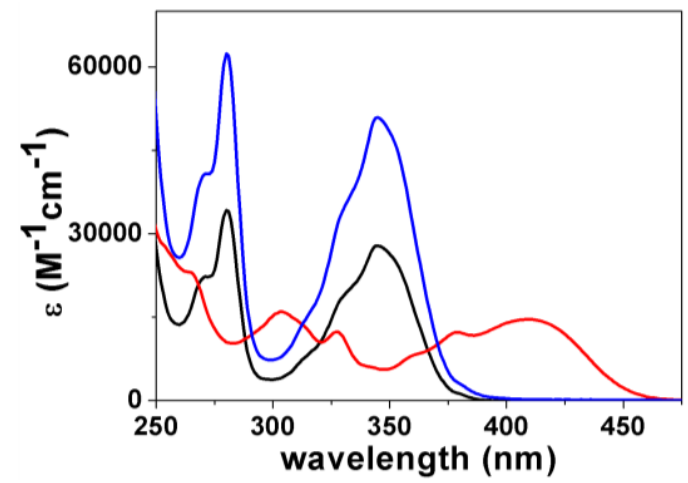

(a)

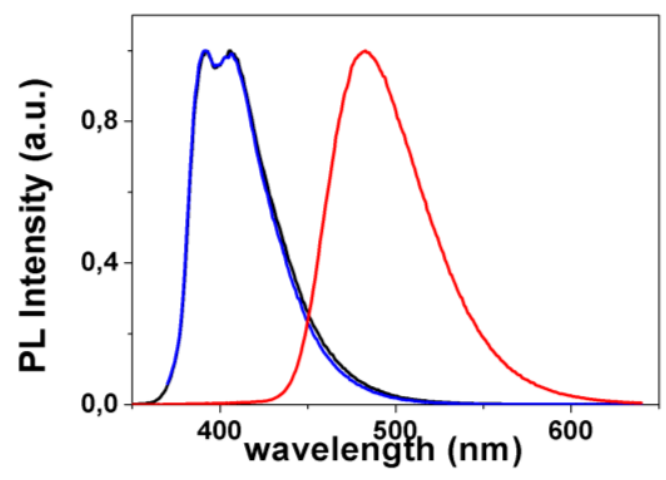

(b)

Figure 2. (a): Absorption spectra in $\mathrm{CHCl}_{3}$ solution of $\mathbf{L}_{\mathbf{1}}$ (black line), [ $\left.\mathbf{L}_{\mathbf{1}} \mathbf{H}\right]^{+}$(red line), and $\mathbf{Z n L}_{\mathbf{1}}$ (blue line); (b): Emission spectra in $\mathrm{CHCl}_{3}$ solution of $\mathbf{L}_{\mathbf{1}}$ (black line), $\left[\mathrm{L}_{\mathbf{1}} \mathbf{H}\right]^{+}$(red line), and $\mathbf{Z n L}_{\mathbf{1}}$ (blue line).

The $\mu \beta_{\lambda}$ of $\mathbf{L}_{1}$ and $\left[\mathbf{L}_{\mathbf{1}} \mathbf{H}\right]^{+}$in $\mathrm{CHCl}_{3}$ solutions were measured at $1907 \mathrm{~nm}$ non-resonant wavelength by the EFISH method, which was recently proven to be a successful alternative to hyper Rayleigh scattering (HRS) to determine protonation-deprotonation NLO contrasts $[8,9,15]$. A $\mu \beta_{\lambda}$ equal to $640 \times 10^{-48}$ esu was found for $\mathrm{L}_{1}$ (at $10^{-3} \mathrm{M}$ in $\mathrm{CHCl}_{3}$ treated overnight with basic $\mathrm{Al}_{2} \mathrm{O}_{3}$ ). After the $\mathbf{L}_{1} \mathrm{CHCl}_{3}$ solution was exposed to $\mathrm{HCl}$ vapors, an inversion of the sign of $\mu \beta_{\lambda}$ was observed $\left(-460 \times 10^{-48} \mathrm{esu}\right)$. To rationalize this observation, DFT, TDDFT and CPKS calculations have been performed on both the optimized charged $\left[\mathrm{L}_{1} \mathrm{H}\right]^{+}$and neutral $\left[\mathrm{L}_{1} \mathrm{HCl}\right]$ model systems that can be compared with the optimized $\mathbf{L}_{\mathbf{1}}$ one. The first system should simulate a broken ionic pair, while the second one a strongly interacting pair. The lowest excitation energy of $\mathbf{L}_{\mathbf{1}}$ was computed at $348 \mathrm{~nm}$, in perfect agreement with the experimental value, and a positive but small $\beta_{\mid ।}(\mathrm{z})$ value $\left(3 \times 10^{-30} \mathrm{esu}\right)$ was obtained. Going to the simulated protonated forms, on one side calculations on $\left[\mathrm{L}_{1} \mathrm{H}\right]^{+}$provided a negative $\beta_{\text {। । }}(\mathrm{z})$ value $\left(-88 \times 10^{-30} \mathrm{esu}\right)$, in agreement with the experimental observations, but too much red-shifted lower energy absorption $\left(\mathrm{S}_{0} \rightarrow \mathrm{S}_{1}\right.$ excitation computed at $\left.549 \mathrm{~nm}\right)$. On the other side, for $\left[\mathrm{L}_{1} \mathrm{HCl}\right]$ the $\beta_{\text {।। }}(\mathrm{z})$ value was positive $\left(9 \times 10^{-30} \mathrm{esu}\right)$ and the $\mathrm{S}_{0} \rightarrow \mathrm{S}_{1}$ excitation energy $(366 \mathrm{~nm})$ was strongly blue-shifted with respect to the experimental value. On the basis of the comparison between experimental and computed spectra, this study indicates that a realistic description of the protonated form of $\mathbf{L}_{\mathbf{1}}$ (i.e., which takes into proper account neglected environment effects) is somehow intermediate to those achievable by our simulations. In fact, though a complete disruption of the ionic pair is to be discarded, an interaction of $\left[\mathrm{L}_{1} \mathrm{H}\right]^{+}$with the $\mathrm{Cl}^{-}$anion should be expected, though weaker than that described by $\left[\mathrm{L}_{1} \mathrm{HCl}\right]$. This interaction produces the observed inversion in the sign of $\mu \beta_{\lambda}$ together with a moderate red-shift of the lower-energy absorption band [15].

The pyridine moiety was further exploited to investigate the modulation of the linear and NLO response after coordination to the $\mathrm{Zn}$ (II) metal center. The complex was prepared by reacting $\mathbf{L}_{1}$ with $\mathrm{Zn}\left(\mathrm{CH}_{3} \mathrm{CO}_{2}\right)_{2}$ at room temperature in $\mathrm{CH}_{2} \mathrm{Cl}_{2}$ to afford the corresponding derivative $\left[\mathrm{Zn}\left(\mathrm{CH}_{3} \mathrm{CO}_{2}\right)_{2}\left(\mathbf{L}_{1}\right)_{2}\right]\left(\mathbf{Z n L}_{\mathbf{1}}\right) .{ }^{1} \mathrm{H}$ NMR spectroscopy revealed a shift to lower field of the signals of the pyridine ring ( $\delta$ in $\mathrm{CDCl}_{3} 8.93$ and $7.72 \mathrm{ppm}$ ) with respect to the free ligand $\mathbf{L}_{\mathbf{1}}$ ( $\delta$ in $\mathrm{CDCl}_{3}$ 
8.83 and $7.63 \mathrm{ppm}$, see Figure S1 in the Supplementary Materials). Single crystals of $\mathbf{Z n L}_{\mathbf{1}}$ suitable for single crystal $\mathrm{X}$-ray diffraction analysis were obtained by recrystallization from $\mathrm{CH}_{2} \mathrm{Cl}_{2} /$ methanol solution (see Figure $1 \mathrm{~b}$ and Figure S5, Table S1). The crystal structure of $\mathbf{Z n L}_{\mathbf{1}}$ consisted of mononuclear complexes with $\mathrm{N}_{2} \mathrm{O}_{2}$-tetrahedral coordination of the $\mathrm{Zn}$ (II) atom, which was created by the nitrogen atoms of the two $\mathbf{L}_{\mathbf{1}}$ ligands and two oxygen atoms of the acetate anions. The asymmetric unit comprised half a molecule, and generated the full one by a mirror plane through the $\mathrm{Zn}$ (II) atom and one acetate ion residing on special position. The other acetate ion was disordered over two positions. The coordination bond lengths ( $\mathrm{Zn}-\mathrm{N}, 2.054(2) \AA ; \mathrm{Zn}-\mathrm{O}(\mathrm{Ac}), 1.931(3), 1.960(5)$ and 1.991(18) $\AA$ ) were close to those observed for analogous $\mathrm{Zn}(\mathrm{II})$ complexes of pyridine-based ligands [16]. A comparison with the molecular structure of $\mathbf{L}_{1}$ revealed that the ligand did not undergo significant variations upon coordination. Particularly in $\mathbf{Z n L}_{1}$ the bond connecting pyrene and pyridine, $r(C 1-C 17)=1.480 \AA$, was almost unvaried and the two aromatic units were only slightly more coplanar $\left(\theta=47.58^{\circ}\right)$ with respect to what was observed for $\mathbf{L}_{\mathbf{1}}$, most probably as a consequence of the different packing of the two structures. Crystal packing of $\mathbf{Z n L}_{\mathbf{1}}$ was governed by $\pi \cdots \pi$ interactions between the pyrene units of adjacent complexes along the $c$-axis, forming infinite zig-zag chains along this direction. The distance between pyrene 1.s. planes, $3.394 \AA$, was shorter than that found in the structure of the free ligand, though the interacting units were slightly more slipped in $\mathbf{Z n L}_{\mathbf{1}}$ with respect to $\mathbf{L}_{\mathbf{1}}$ (the distance between centroids of the pyrene rings was equal to $4.189 \AA$ ).

Similar to what was previously reported for the " $\mathrm{Zn}\left(\mathrm{CH}_{3} \mathrm{CO}_{2}\right)_{2}$ " derivative with 4-trans- $-\mathrm{NC}_{5} \mathrm{H}_{4} \mathrm{CH}=\mathrm{CHC}_{6} \mathrm{H}_{4}-4^{\prime}-\mathrm{NMe}_{2}$ stilbazole ligand [17], no changes were observed in the absorption and emission spectra of $\mathbf{Z n L}_{\mathbf{1}}$ with respect to the $\mathbf{L}_{\mathbf{1}}$ ligand itself (see Table 1). This behavior was related to the tetrahedral arrangement of the complex, for which no remarkable effect on $\Delta \lambda_{\max }$ of the ligand could be observed, as opposed to the pseudolinear coordination motifs and notwithstanding the Lewis acidity of the metal center. This observation was rather well-reproduced by (TD)PBE0/6-311++G(d,p) calculations on $\mathbf{Z n L}_{1}$. The lowest-energy computed transition, only slightly red-shifted (by $17 \mathrm{~nm}$ ) with respect to that of $\mathbf{L}_{1}$, showed ILCT character with no involvement of the Zn atom.

EFISH measurements on a $10^{-3} \mathrm{M} \mathrm{CHCl}_{3}$ solution of $\mathrm{ZnL}_{1}$ revealed a negative $\mu \beta_{\lambda}$ value $\left(-250 \times 10^{-48} \mathrm{esu}\right)$, smaller (in absolute value) than that of $\left[\mathbf{L}_{\mathbf{1}} \mathbf{H}\right]^{+}$in agreement with the weak Lewis acidity of the " $\mathrm{Zn}\left(\mathrm{CH}_{3} \mathrm{CO}_{2}\right)_{2}$ " fragment [18].

Table 1. Linear and nonlinear optical properties of $\mathbf{L}_{1}, \mathbf{L}_{2}$, and their derivatives together with pyrene and PVP reference compounds.

\begin{tabular}{|c|c|c|c|}
\hline Compound & $\lambda_{\mathrm{abs}}(\mathrm{nm})$ & $\lambda_{\mathrm{em}}{ }^{\mathrm{a}}(\mathrm{nm})$ & $\mu \beta_{\lambda}\left(10^{-48} \mathrm{esu}\right)$ \\
\hline Pyrene & $337,322,309,274,264$ & $415,394,385,374^{b}$ & - \\
\hline PVP ${ }^{c}$ & $378(\mathrm{br})$ & 450 & 1500 \\
\hline$[\mathrm{PVPH}]^{+\mathrm{c}}$ & 443,395 & 550 & -950 \\
\hline $\mathbf{L}_{1}$ & $345,330(\mathrm{sh}), 314(\mathrm{sh}), 280,270(\mathrm{sh})$ & 407,390 & $650 \pm 156$ \\
\hline$\left[\mathrm{L}_{1} \mathrm{H}\right]^{+}$ & $410,380,328,304$ & 482 & $-460 \pm 78$ \\
\hline $\mathrm{ZnL}_{1}$ & $345,330(\mathrm{sh}), 314(\mathrm{sh}), 280,270(\mathrm{sh})$ & 407,390 & $-250 \pm 42$ \\
\hline $\mathbf{L}_{2}$ & $345,328,314,277,266$ & $440(\mathrm{sh}), 415(\mathrm{sh}), 396,377$ & $197 \pm 73$ \\
\hline$\left[\mathrm{L}_{2} \mathrm{H}\right]^{+}$ & $345,328,314,277,266$ & 496 & $-270 \pm 62$ \\
\hline $\mathrm{CuL}_{2}$ & $345,328,314,277,266$ & 443(sh), 416(sh), 397, 377 & - \\
\hline
\end{tabular}

\subsection{Synthesis and Characterization of $\mathrm{L}_{2},\left[\mathrm{~L}_{2} \mathrm{H}\right]^{+}$, and $\mathrm{CuL_{2 }}$}

Compound $\mathbf{L}_{2}$ was synthesized as reported in the literature [13] by the hydrogenation of PVP (see Scheme 3). In $\mathbf{L}_{2}$ no conjugation was expected between the aromatic systems due to the interconnecting dimethylene bridge. From single-crystal XRD analysis (see Figure 3a and Figure S6, Table S1), the dihedral angle between the l.s. planes through pyrene and pyridine measured $\theta=89.08^{\circ}$. Molecules of $\mathbf{L}_{2}$ formed infinite chains along the crystallographic axis $\mathrm{c}$ through $\mathrm{C}-\mathrm{H} \cdots \pi$ hydrogen 
bonds connecting pyridine with the $\pi$-electron system of pyrene (distance between $\mathrm{H} 20$ and the pyrene 1.s. plane equal to $2.91 \AA$ ). These chains were laterally connected through weak van der Waals contacts, with the pyrene units showing a large slippage (distance between respective centroids equal to $7.214 \AA$ ) though placed at interplanar distance equal to $3.551 \AA$.

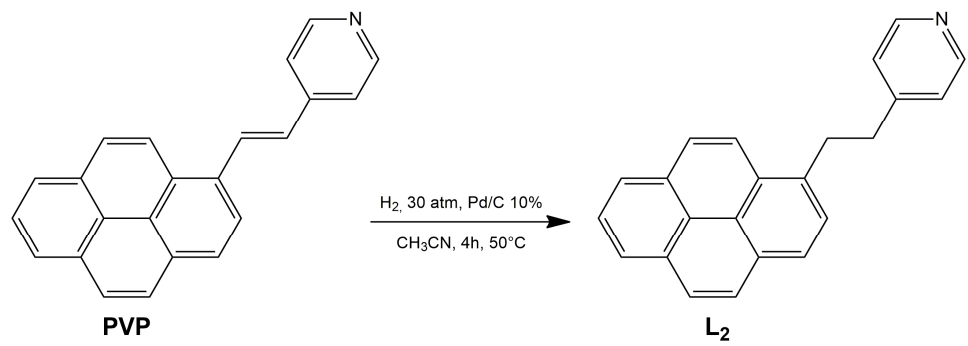

Scheme 3. Synthesis of $\mathbf{L}_{2}$.
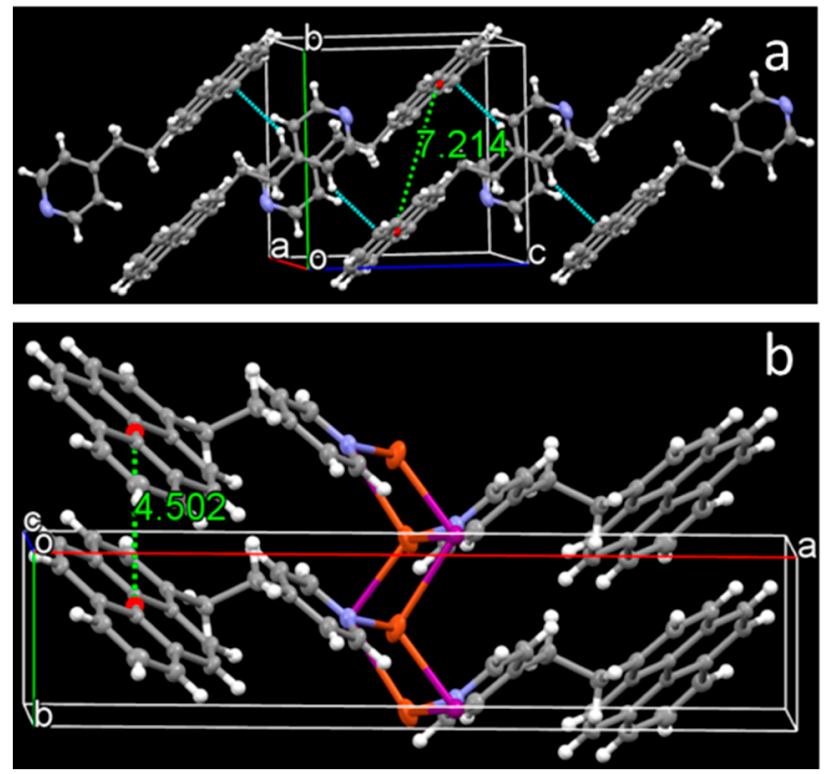

Figure 3. Fragments of the crystal packing of (a) $\mathbf{L}_{2}$ (viewed approximately along the a direction) and (b) $\mathrm{CuL}_{2}$ (viewed approximately along the c direction) showing $\mathrm{C}-\mathrm{H} \cdots \pi$ hydrogen bonds (light blue dashed lines) and distance between centroids of the pyrene units (green dashed line). Ellipsoids drawn at $30 \%$ probability.

A comparison of the absorption spectra of $\mathbf{L}_{2}$ and $\mathbf{P V P}$ in $\mathrm{CHCl}_{3}$ showed that, due to the loss of conjugation by hydrogenation of the ethylene bridge, the structureless features were here resolved in two sets of vibronic bands centered at 345 and $277 \mathrm{~nm}$ (see Figure $4 \mathrm{a}$ and Table 1). These bands, slightly red-shifted from those of the pyrene moiety, were not affected when exposing a $\mathrm{CHCl}_{3}$ solution of $\mathbf{L}_{2}$ to $\mathrm{HCl}$ vapors. However, the formation of $\left[\mathbf{L}_{2} \mathbf{H}\right]^{+}$could be assessed by the expected ${ }^{1} \mathrm{H} N M R$ appearance of a signal at $18.16 \mathrm{ppm}$ for the $\mathrm{NH}^{+}$moiety and by the shift to lower field of the pyridine signals ( $\delta$ in $\mathrm{CDCl}_{3} 8.53$ and $7.50 \mathrm{ppm}$ ) with respect to the free ligand $\mathrm{L}_{2}$ ( $\delta$ in $\mathrm{CDCl}_{3} 8.51$ and $7.14 \mathrm{ppm}$, see Figure S2). Additionally, a broad band centered at $496 \mathrm{~nm}$ appeared in the emission spectrum. This fluorescence can be assigned to an "exciplex" formed between the pyrene and pyridinium moieties, in agreement with previous findings [20]. The loss of push-pull character for $\mathbf{L}_{2}$ in comparison with PVP was supported by EFISH measurements which revealed a $\mu \beta_{\lambda}$ of $197 \times 10^{-48}$ esu (at $10^{-3} \mathrm{M}^{-4}$ concentration) for the former in comparison with the $1500 \times 10^{-48} \mathrm{esu}$ value of the latter. As in the case of $\left[\mathbf{L}_{\mathbf{1}} \mathbf{H}\right]^{+}$, the protonated species $\left[\mathbf{L}_{2} \mathbf{H}\right]^{+}$displayed a weaker but negative $\mu \beta_{\lambda}\left(-270 \times 10^{-48}\right.$ esu). DFT, TDDFT, and CPKS calculations on $\mathrm{L}_{2},\left[\mathrm{~L}_{2} \mathrm{H}\right]^{+}$, and $\left[\mathrm{L}_{2} \mathrm{HCl}\right]$ model systems led to similar 
results as those obtained to rationalize the behavior of $\mathbf{L}_{\mathbf{1}}$, except for the lower excitation energy, which in agreement with the experimental findings, did not vary going from $\mathbf{L}_{2}(337 \mathrm{~nm})$ to either $\left[\mathrm{L}_{2} \mathrm{H}\right]^{+}(339 \mathrm{~nm})$ or $\left[\mathrm{L}_{2} \mathrm{HCl}\right](338 \mathrm{~nm})$. However, in contrast to what was obtained for $\mathbf{L}_{\mathbf{1}}$, in this case we were able to converge to a stationary state "intermediate" between $\left[\mathrm{L}_{2} \mathrm{H}\right]^{+}$and $\left[\mathrm{L}_{2} \mathrm{HCl}\right]$ by constraining the $\mathrm{L}_{2}-\mathrm{H}$ and $\mathrm{L}_{2} \mathrm{H}-\mathrm{Cl}$ distances to reasonable values (equal to 1.01 and $3.0 \AA$, respectively). For this system, having a lower excitation energy at $338 \mathrm{~nm}$, a negative $\beta_{\text {।। }}(\mathrm{z})$ value $\left(-6 \times 10^{-30} \mathrm{esu}\right)$ was obtained, in agreement with the experimental measurements.

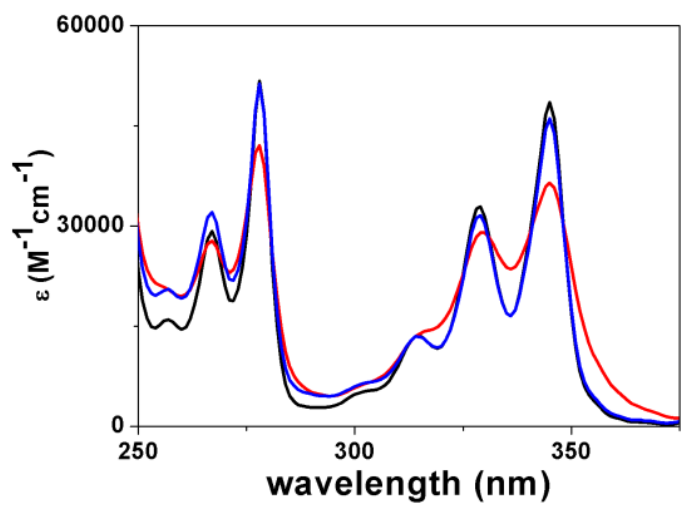

(a)

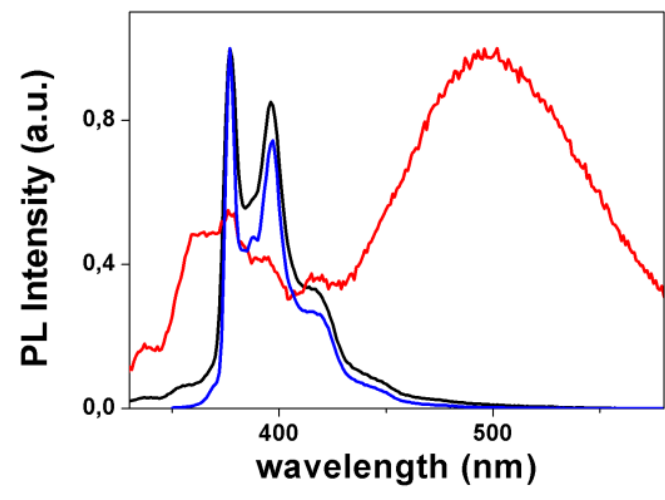

(b)

Figure 4. (a): Absorption spectra in $\mathrm{CHCl}_{3}$ solution of $\mathbf{L}_{2}$ (black line), $\left[\mathbf{L}_{2} \mathbf{H}\right]^{+}$(red line), and $\mathbf{C u L}_{2}$ (blue line); (b): Emission spectra in $\mathrm{CHCl}_{3}$ solution of $\mathbf{L}_{2}$ (black line), $\left[\mathbf{L}_{2} \mathbf{H}\right]^{+}$(red line), and $\mathbf{C u L}_{2}$ (blue line).

$\mathbf{L}_{2}$ was further coordinated to $\mathrm{Cu}(\mathrm{I})$ in order to investigate the role of a $\mathrm{d}^{10}$ metal center on the linear and non-linear optical properties of the ligand. By layering a $\mathrm{CH}_{3} \mathrm{CN}$ solution of $\mathbf{L}_{2}$ into a water solution of $\mathrm{CuI}$ in saturated $\mathrm{KI}$, crystals of the coordination polymer $\left[\mathrm{CuI}\left(\mathbf{L}_{2}\right)\right]_{n}\left(\mathrm{CuL}_{2}\right)$ suitable for X-ray diffraction were obtained (see Table S1 and Figure S7). In the crystal structure of $\mathbf{C u L}_{2}$, the well-known double-stranded "stair" motif (see Figure 3b) was observed. Each copper atom was tetracoordinated (to three iodine atoms and the nitrogen of $\mathbf{L}_{2}$ ) in distorted tetrahedral stereochemistry, with $\mathrm{Cu}-\mathrm{I}$ and $\mathrm{Cu}-\mathrm{N}$ bond distances comparable to those of known $[\mathrm{CuI}(\mathrm{L})]_{n}$ stairs [21]. The organic ligand stacked along both sides of the CuI skeleton, undergoing a conformational rearrangement with respect to what was observed in the free ligand structure. In fact, the pyrene and pyridine moieties in $\mathrm{CuL}_{2}$ were almost coplanar $\left(\theta=4.82^{\circ}\right)$ as opposed to the twisted conformation of $\mathbf{L}_{2}$. The pyrene units were placed at quite short interplanar distances $(3.452 \AA)$ with reduced slippage (distance between respective centroids equal to $4.502 \AA$ ).

The formation of the $\mathrm{Cu}(\mathrm{I})$ derivative was confirmed by ${ }^{1} \mathrm{H}$ NMR spectroscopy, which revealed a loss in the resolution of both the pyridine (barely detectable) and the ethane bridge resonances (see Figure S3). However, no remarkable changes could be detected in the absorption and emission spectra, which reveals-as in the case of the free $\mathbf{L}_{2}$ ligand - the vibronic features characteristic of the pyrene moiety.

EFISH measurements in DMF or $\mathrm{CH}_{2} \mathrm{Cl}_{2}$ solutions of the $\mathrm{CuL}_{2}$ coordination polymer gave unexpectedly high and negative values. This unusual second-order response deserves further investigation to exclude the possible formation — under the strong electric field applied during the measurements—of ionic species arising from the $\mathrm{Cu}(\mathrm{I})$ polymer commonly known as labile in solution.

\section{Materials and Methods}

\subsection{Single-Crystal X-ray Crystallographic Studies}

X-ray diffraction data of $\mathbf{L}_{1}, \mathbf{Z n L}_{1}, \mathbf{L}_{2}$, and $\mathbf{C u L}_{2}$ were collected on a Bruker Apex II diffractometer (Bruker AXS Inc., Madison, WI, USA) using Mo K $\alpha$ radiation. The structures were solved using direct methods and were refined by using a full-matrix least squares procedure, based on $\mathrm{F}^{2}$ using 
all data [22]. Hydrogen atoms were placed at geometrically estimated positions. Details relating to the crystals and the structural refinements are presented in Table S1. Full details of crystal data and structure refinement, in CIF format, are available as Supplementary Materials. CCDC reference numbers: $1886755\left(\mathbf{L}_{\mathbf{1}}\right), 1900477\left(\mathbf{Z n L}_{\mathbf{1}}\right), 1886756\left(\mathbf{L}_{2}\right)$, and $1886757\left(\mathbf{C u L}_{\mathbf{2}}\right)$.

\subsection{Computational Details}

DFT and TDDFT calculations on $\mathbf{L}_{\mathbf{1}}$ and $\mathbf{L}_{2}$, together with their protonated forms, and on $\mathbf{Z n L}_{\mathbf{1}}$ were performed with Gaussian 16 program (Revision A.03) [23] using the $6-311++G(d, p)$ basis set. The geometries of the compounds were optimized starting from their respective experimental ones as derived from X-ray studies. Based on previous theoretical results that were obtained on PVP [8], the PBE0 functional $[24,25]$ was used for both DFT and TDDFT calculations, due to its ability to correctly treat ground and excited state properties. Hyperpolarizability ( $\beta$ tensor) was computed within the coupled perturbed Kohn-Sham (CPKS) approach at the same frequency as used in the experiment. For a meaningful comparison with the experimental $\mu \beta_{\lambda}$ values, we report the quantity $\beta_{\text {। I }}(\mathrm{z})=1 / 5 \sum_{j}\left(\beta_{z j j}+\beta_{j z j}+\beta_{j j z}\right)$, that is, the projection along the $\mathrm{z}$-axis of a "vector" derived from the full $\beta$ tensor, with the molecule oriented with its dipole along the z-axis. In particular, for a linear push-pull molecule a positive $\beta_{\|}(\mathrm{z})$ value indicates that the associated vector is oriented in the same direction as the dipole moment vector, whilst a negative one corresponds to vectors oriented in opposite directions. We adopted the CAM-B3LYP functional [26], which has recently been recommended for hyperpolarizability calculations of mid-size organic chromophores [27]. A pruned $(99,590)$ grid was selected for the computation and use of two-electron integrals and their derivatives.

\subsection{EFISH Measurements}

EFISH measurements [28] were carried out in $\mathrm{CHCl}_{3}$ (treated with basic $\mathrm{Al}_{2} \mathrm{O}_{3}$ before use) with a non-resonant incident wavelength of $1907 \mathrm{~nm}$, obtained by Raman-shifting the fundamental $1064 \mathrm{~nm}$ wavelength produced by a Q-switched, mode-locked $\mathrm{Nd}^{3+}$ :YAG laser. The $\mu \beta_{\lambda}$ values reported are the mean values of four measurements performed on the same sample.

\section{Conclusions}

Our previous findings on the linear and NLO optical properties of pyrene-pyridine chromophores were here extended to $\mathbf{L}_{1}$, with the pyridine directly bound to the pyrene moiety and to $\mathbf{L}_{2}$, where the dimethylene bridge connecting the aromatic systems breaks the conjugation between them. Similar to what was observed for PVP, their NLO response could be switched by performing protonation/deprotonation cycles, with a change in the sign of $\mu \beta_{\lambda}$ for both protonated forms, although greater in absolute value for $\mathbf{L}_{1}$ due to its push-pull character. Coordination of $\mathbf{L}_{1}$ to $\mathrm{Zn}$ (II) metal center to form the monomeric $\mathbf{Z n L}_{\mathbf{1}}$ complex also induced a change in the sign of $\mu \beta_{\lambda}$, although the weak Lewis acidity of the $\mathrm{Zn}$ (II) fragment resulted in a smaller absolute value when compared to the protonated form. Coordination of $\mathbf{L}_{2}$ to $\mathrm{Cu}(\mathrm{I})$ metal center gave rise to the formation of the $\left[\mathrm{CuI}\left(\mathbf{L}_{2}\right)\right]_{n}$ coordination polymer, showing the well-known double-stranded "stair" motif in its crystal structure. EFISH measurements on this $\mathrm{Cu}(\mathrm{I})$ polymer gave an unexpectedly high and negative second-order response, which deserves further investigation.

Supplementary Materials: The following are available online at http:/ / www.mdpi.com/2304-6740/7/3/38/s1, Experimental Procedures, Figure S1: Expanded region of ${ }^{1} \mathrm{H}$ NMR spectra of $\mathbf{L}_{\mathbf{1}}$ and $\mathbf{Z n L} \mathbf{L}_{\mathbf{1}}$, Figure S2: ${ }^{1} \mathrm{H}$ NMR spectra of $\mathbf{L}_{2}$ and $\left[\mathbf{L}_{2} \mathbf{H}\right]^{+}$, Figure S3: ${ }^{1} \mathrm{H}$ NMR spectra of $\mathbf{L}_{2}$ and $\mathbf{C u L}_{2}$, Figure S4: ORTEP view of $\mathbf{L}_{1}$ with atom labelling scheme, Figure S5: ORTEP view of $\mathbf{Z n L}_{\mathbf{1}}$ with atom labelling scheme, Figure S6: ORTEP view of $\mathbf{L}_{2}$ with atom labelling scheme, Figure S7: ORTEP view of $\mathbf{C u L}_{2}$ with atom labelling scheme, Table S1: Crystallographic data and structure refinement details for $\mathbf{L}_{1}, \mathbf{Z n L}_{1}, \mathbf{L}_{2}$ and $\mathbf{C u L _ { 2 }}$.

Author Contributions: E.L. performed the syntheses (lead) and contributed to write the paper, A.F. performed the X-ray single crystal structural characterizations and quantum-mechanical calculations (lead) and contributed to interpreting the results and to writing the paper, D.M. performed the photophysical measurements, A.P. performed 
the syntheses, S.R. performed the EFISH and photophysical measurements, E.C. conceived and designed the experiments and contributed to interpreting the results and to writing the paper.

Funding: This research received no external funding.

Acknowledgments: We are grateful to Renato Ugo for the example he is giving us in chemistry and in life. The authors thank Dominique Roberto for fruitful discussions and Luca Pignataro for help in performing hydrogenation reactions. The use of instrumentation purchased through the Regione Lombardia-Fondazione Cariplo joint SmartMatLab Project is gratefully acknowledged.

Conflicts of Interest: The authors declare no conflict of interest.

\section{References}

1. Papadopoulos, M.G.; Sadlej, A.J.; Leszczynski, J. Non-Linear Optical Properties of Matter; Springer: Dordrecht, The Netherlands, 2006.

2. Zyss, J. Molecular Nonlinear Optics: Materials, Physics, and Devices; Academic Press: Boston, MA, USA, 1994.

3. Lesley, M.J.G.; Woodward, A.; Taylor, N.J.; Marder, T.B.; Cazenobe, I.; Ledoux, I.; Zyss, J.; Thornton, A.; Bruce, D.W.; Kakkar, A.K. Lewis Acidic Borane Adducts of Pyridines and Stilbazoles for Nonlinear Optics. Chem. Mater. 1998, 10, 1355-1365. [CrossRef]

4. Evans, O.R.; Lin, W. Crystal Engineering of NLO Materials Based on Metal-Organic Coordination Networks. Acc. Chem. Res. 2002, 35, 511-522. [CrossRef] [PubMed]

5. Cariati, E.; Pizzotti, M.; Roberto, D.; Tessore, F.; Ugo, R. Coordination and organometallic compounds and inorganic-organic hybrid crystalline materials for second-order non-linear optics. Coord. Chem. Rev. 2006, 250, 1210-1233. [CrossRef]

6. Kanis, D.R.; Lacroix, P.G.; Ratner, M.A.; Marks, T.J. Electronic Structure and Quadratic Hyperpolarizabilities in Organotransition-Metal Chromophores Having Weakly Coupled $\pi$-Networks. Unusual Mechanisms for Second-Order Response. J. Am. Chem. Soc. 1994, 116, 10089-10102. [CrossRef]

7. Roberto, D.; Ugo, R.; Bruni, S.; Cariati, E.; Cariati, F.; Fantucci, P.; Invernizzi, I.; Quici, S.; Ledoux, I.; Zyss, J. Quadratic Hyperpolarizability Enhancement of para-Substituted Pyridines upon Coordination to Organometallic Moieties: The Ambivalent Donor or Acceptor Role of the Metal. Organometallics 2000, 19, 1775-1788. [CrossRef]

8. Cariati, E.; Botta, C.; Danelli, S.G.; Forni, A.; Giaretta, A.; Giovanella, U.; Lucenti, E.; Marinotto, D.; Righetto, S.; Ugo, R. Solid state and solution fine tuning of the linear and nonlinear optical properties of (2-pyrene-1-yl-vinyl)pyridine by protonation-deprotonation reactions. Chem. Commun. 2014, 50, 14225-14228. [CrossRef] [PubMed]

9. Cariati, E.; Dragonetti, C.; Lucenti, E.; Nisic, F.; Righetto, S.; Roberto, D.; Tordin, E. An acido-triggered reversible luminescent and nonlinear optical switch based on a substituted styrylpyridine: EFISH measurements as an unusual method to reveal a protonation-deprotonation NLO contrast. Chem. Commun. 2014, 50, 1608. [CrossRef] [PubMed]

10. Creus, J.; Matheu, R.; Peñafiel, I.; Moonshiram, D.; Blondeau, P.; Benet-Buchholz, J.; García-Antón, J.; Sala, X.; Godard, C.; Llobet, A. A Million Turnover Molecular Anode for Catalytic Water Oxidation. Angew. Chem. Int. Ed. 2016, 55, 15382-15386. [CrossRef]

11. Hüglin, D.; Seiffert, W.; Zimmermann, H.W. Time-resolved microfluorometric study of the binding sites of lipophilic cationic pyrene probes in mitochondria of living HeLa cells. J. Photochem. Photobiol. B Biol. 1995, 31, 145-158. [CrossRef]

12. Sankaran, N.B.; Banthia, S.; Das, A.; Samanta, A. Fluorescence signaling of transition metal ions: A new approach. New J. Chem. 2002, 26, 1529-1531. [CrossRef]

13. Sankaran, N.B.; Das, A.; Samanta, A. Interaction between a pyridyl and a naphthyl/pyrenyl moiety in covalently linked systems. Chem. Phys. Lett. 2002, 351, 61-70. [CrossRef]

14. Camerman, A.; Trotter, J. The crystal and molecular structure of pyrene. Acta Cryst. 1965, 18, $636-643$. [CrossRef]

15. Pielak, K.; Tonnelé, C.; Sanguinet, L.; Cariati, E.; Righetto, S.; Muccioli, L.; Castet, F.; Champagne, B. Dynamical Behavior and Second Harmonic Generation Responses in Acido-Triggered Molecular Switches. J. Phys. Chem. 2018, 122, 26160-26168. [CrossRef] 
16. Dojer, B.; Pevec, A.; Belaj, F.; Kristl, M. Two new zinc(II) acetates with 3- and 4-aminopyridine: Syntheses and structural properties. Acta Chim. Slov. 2015, 62, 312-318. [CrossRef] [PubMed]

17. Roberto, D.; Ugo, R.; Tessore, F.; Lucenti, E.; Quici, S.; Vezza, S.; Fantucci, P.; Invernizzi, I.; Bruni, S.; Ledoux-Rak, I.; et al. Effect of the Coordination to $\mathrm{M}(\mathrm{II})$ Metal Centers $(\mathrm{M}=\mathrm{Zn}, \mathrm{Cd}, \mathrm{Pt})$ on the Quadratic Hyperpolarizability of Various Substituted 5-X-1,10-phenanthrolines ( $\mathrm{X}=$ Donor Group) and of trans-4-(Dimethylamino)-4'-stilbazole. Organometallics 2002, 21, 161-170. [CrossRef]

18. Di Bella, S.; Colombo, A.; Dragonetti, C.; Righetto, S.; Roberto, D. Zinc(II) as a Versatile Template for Efficient Dipolar and Octupolar Second-Order Nonlinear Optical Molecular Materials. Inorganics 2018, 6, 133. [CrossRef]

19. Kollár, J.; Hrdlovič, P.; Chmela, Š. Spectral properties of bichromophoric pyrene derivatives: Monomer vs. excimer fluorescence. J. Photochem. Photobiol. Chem. 2010, 214, 33-39. [CrossRef]

20. Filby, M.H.; Dickson, S.J.; Zaccheroni, N.; Prodi, L.; Bonacchi, S.; Montalti, M.; Paterson, M.J.; Humphries, T.D.; Chiorboli, C.; Steed, J.W. Induced Fit Interanion Discrimination by Binding-Induced Excimer Formation. J. Am. Chem. Soc. 2008, 130, 4105-4113. [CrossRef]

21. Cariati, E.; Roberto, D.; Ugo, R.; Ford, P.C.; Galli, S.; Sironi, A. New Structural Motifs, Unusual Quenching of the Emission, and Second Harmonic Generation of Copper(I) Iodide Polymeric or Oligomeric Adducts with Para-Substituted Pyridines or trans-Stilbazoles. Inorg. Chem. 2005, 44, 4077-4085. [CrossRef]

22. Sheldrick, G.M. Crystal structure refinement with SHELXL. Acta Crystallogr. Struct. Chem. 2015, 71, 3-8. [CrossRef]

23. Frisch, M.J.; Trucks, G.W.; Schlegel, H.B.; Scuseria, G.E.; Robb, M.A.; Cheeseman, J.R.; Scalmani, G.; Barone, V.; Petersson, G.A.; Nakatsuji, H.X.; et al. Gaussian 16, Revision A.03; Gaussian: Wallingford, CT, USA, 2016.

24. Adamo, C.; Barone, V. Toward reliable density functional methods without adjustable parameters: The PBE0 model. J. Chem. Phys. 1999, 110, 6158-6170. [CrossRef]

25. Ernzerhof, M.; Scuseria, G.E. Assessment of the Perdew-Burke-Ernzerhof exchange-correlation functional. J. Chem. Phys. 1999, 110, 5029-5036. [CrossRef]

26. Yanai, T.; Tew, D.P.; Handy, N.C. A new hybrid exchange-correlation functional using the Coulomb-attenuating method (CAM-B3LYP). Chem. Phys. Lett. 2004, 393, 51-57. [CrossRef]

27. Johnson, L.E.; Dalton, L.R.; Robinson, B.H. Optimizing Calculations of Electronic Excitations and Relative Hyperpolarizabilities of Electrooptic Chromophores. Acc. Chem. Res. 2014, 47, 3258-3265. [CrossRef] [PubMed]

28. Ledoux, I.; Zyss, J. Influence of the molecular environment in solution measurements of the Second-order optical susceptibility for urea and derivatives. Chem. Phys. 1982, 73, 203-213. [CrossRef] 